\title{
Hepatitis $B$ revaccination for healthcare workers who are anti-HBs-negative after receiving a primary vaccination series
}

\author{
Marta Heloisa Lopes ${ }^{[1],[2]}$, Ana Marli Christovam Sartori ${ }^{[1]}$, Tatiany Viviany Gonçalves Souza ${ }^{[1]}$, \\ Melissa Mascheretti ${ }^{[1]}$ and Tânia do Socorro Souza Chaves ${ }^{[1]}$
}

[1]. Centro de Referência para Imunobiológicos Especiais e Divisão de Clínica de Moléstias Infecciosas e Parasitárias, Hospital das Clínicas, Faculdade de Medicina, Universidade de São Paulo, São Paulo, SP. [2]. Departamento de Moléstias Infecciosas e Parasitárias, Faculdade de Medicina, Universidade de São Paulo, São Paulo, SP.

\section{ABSTRACT}

Introduction: This study aimed to evaluate the response to hepatitis B (HB) revaccination of healthcare workers (HCW) who are negative for antibodies to HB surface antigen (anti-HBs) after a complete vaccination series. Methods: HCW whose anti-HBs test was performed $>90$ days after a HB vaccination course were given a $4^{\text {th }}$ dose. A post-vaccination test was done within 30 to 90 days. Results: One hundred and seventy HCW were enrolled: $126(74.1 \%)$ were anti-HBs-positive after the $4^{\text {th }}$ dose. Conclusions: Rechecking anti-HBs after the $4^{\text {th }}$ HB vaccine dose is a practical approach in case of post-vaccination tests performed $>90$ days after the full vaccination course.

Keywords: Hepatitis B vaccination. Healthcare workers.

A primary 3-dose hepatitis $B(H B)$ vaccination series induces protective serum levels of antibodies to HB surface antigen (anti$\mathrm{HBs} \geq 10 \mathrm{mUI} / \mathrm{mL}$ ) in $90 \%$ of healthy adults and $95 \%$ of children and adolescents. $A 2^{\text {nd }}$ full-course vaccination induces protection in $\geq 50 \%$ of those who did not respond to the $1^{\text {st }}$ vaccination series ${ }^{1}$. Vaccineinduced antibodies to HB decline over time: Up to $60 \%$ of persons who initially respond to the vaccine will lose detectable antibodies over 5 to 15 years (waning immunity)2. Despite the decline of anti$\mathrm{HBs}$ concentration to $<10 \mathrm{mUI} / \mathrm{mL}$, persons who initially responded to the $\mathrm{HB}$ vaccine remain protected against chronic $\mathrm{HB}$ infection due to immune memory3.

Hepatitis B vaccination is recommended for all healthcare workers (HCW) who have a chance of exposure to blood or body fluids. Postvaccination testing for anti-HBs is recommended for persons whose subsequent clinical management depends on knowledge of their immune status, such as healthcare personnel ${ }^{1}$. When recommended, post-vaccination testing should be performed within 30 to 90 days of the last dose of the vaccine ${ }^{1}$.

Healthcare workers frequently do not perform post-vaccination anti-HBs testing. Although $\mathrm{HB}$ vaccination has been recommended for HCW since the 1980s, routine post-vaccination testing has not yet been incorporated in the care of HCW in Brazil. Additionally, the adherence of $\mathrm{HCW}$ to vaccination and post-vaccination testing is poor. Furthermore, the frequency of HCW who were vaccinated when they were children or adolescents is increasing, and post-vaccination testing is not recommended in routine $\mathrm{HB}$ immunization.

In the management of HCW who are anti-HBs-negative after a full-course vaccination, the first step is to check the interval between

\footnotetext{
Address to: Dra. Ana Marli Christovam Sartori. PAMB. Av. Enéas de Carvalho Aguiar 255/40 andar, Bloco 8, Cerqueira César, 05403-000 São Paulo, SP, Brasil.

Phone/Fax: 5511 3069-7517

e-mail: anasartori@gmail.com

Received in 28/12/2010

Accepted in 01/02/2011
}

the last dose of $H B$ vaccine and the post-vaccination testing. If it exceeds 6 months, a single dose of $\mathrm{HB}$ vaccine helps to differentiate between non-response and waning immunity. A booster dose of the vaccine induces an anamnestic response among persons with waning immunity, whereas non-responders will have no detectable serum anti-HBs or a very small rise ${ }^{4-6}$. Persons who are anti-HBs-negative after the $4^{\text {th }}$ dose of $\mathrm{HB}$ vaccine should receive two more doses. Those who present as anti-HBs-negative after a $2^{\text {nd }}$ full vaccination course (total of 6 doses) are considered true non-responders ${ }^{4}$.

The aim of this study was to evaluate the response to hepatitis $B$ revaccination among $\mathrm{HCW}$ who are anti-HBs-negative after receiving a primary 3-dose $\mathrm{HB}$ vaccination series at any time in the past.

This prospective study was conducted at the Centro de Referência para Imunobiológicos Especiais of Hospital das Clínicas (CRIE-HC), a tertiary teaching hospital attached to the Faculdade de Medicina of Universidade de São Paulo, in the City of São Paulo, southeast of Brazil, from February 2006 to September 2007.

In this hospital, HCW who are anti-HBs-negative $(<10 \mathrm{mIU} / \mathrm{mL})$ in routine assessment by the occupational health service are referred to the CRIE to have their vaccination status evaluated. HCW who are anti-HBs-negative and who reported a prior 3-dose HB vaccination series at any time in the past were asked whether they had had a previous post-vaccination test. We also searched for previous anti-HBs tests in the hospital laboratory database. HCW who were previously documented as anti-HBs-positive $(\geq 10 \mathrm{mIU} / \mathrm{mL})$ were considered protected. HCW who had not been tested before or who did not know whether they were tested or not were administered a $4^{\text {th }}$ dose of HB vaccine and were invited to participate in this study.

All enrolled subjects were asked to draw blood samples for the anti-HBs test (ELISA) 30 to 90 days after the $4^{\text {th }}$ dose of the vaccine, according to a previously proposed algorithm ${ }^{4}$. HCW who developed anti-HBs $\geq 10 \mathrm{mIU} / \mathrm{mL}$ following the $4^{\text {th }}$ dose of the vaccine were considered protected. HCW who were anti-HBs-negative after the $4^{\text {th }}$ dose of $\mathrm{HB}$ vaccine were given two more doses of the vaccine and had 
their anti-HBs level rechecked 30 to 90 days after the $6^{\text {th }}$ dose. HCW who were anti-HBs-negative following the $6^{\text {th }}$ dose of $\mathrm{HB}$ vaccine were considered true non-responders.

The study was approved by the Ethical Committee of the Hospital das Clínicas of the Faculdade de Medicina of Universidade de São Paulo. All subjects signed an informed consent form before enrollment in the study.

A total of $170 \mathrm{HCW}$ who were anti-HBs-negative following a 3-dose primary $\mathrm{HB}$ vaccination series were enrolled in the study. There were 60 staff nurses, 21 medical doctors, 28 specialized technicians (physiotherapists and laboratory, X-ray, and pharmacy staff), 21 general services staff (cleaning, laundry, operational services, and kitchen), 12 administrative personnel, 26 medical and nursing students, and 1 retired HCW (the occupation was not informed for 1 subject).

All of them received a $4^{\text {th }}$ dose of the HB vaccine, but only 151 collected blood for post-vaccination anti-HBs retesting (the interval between the $4^{\text {th }}$ dose of $\mathrm{HB}$ vaccine and the test ranged from 1 to 22 months, with a mean of 3.2 months): 126 (83.4\%) were antiHBs-positive $(\geq 10 \mathrm{mlU} / \mathrm{mL})$ and $25(16.6 \%)$ were anti-HBs-negative. Table 1 shows the demographic characteristics of the subjects and the interval between the $3^{\text {rd }}$ dose of $\mathrm{HB}$ vaccine and the anti-HBs negative test, according to the subjects' anti-HBs status following the $4^{\text {th }}$ dose of $H B$ vaccine.

Healthcare workers who were anti-HBs-positive following the $4^{\text {th }}$ dose of the vaccine were younger at the time of primary $H B$ vaccination series (mean age, 30.9 ) than those who did not respond to the $4^{\text {th }}$ vaccine dose (mean age, 37), although this difference was not statistically significant (Student's T test, $t=1.865, p=0.065$ ). HCW who did not collect blood for post-vaccination testing were younger (mean age, 23.1) than those who underwent the test (mean age, 31.9), and this difference was statistically significant (Student's T test, $\mathrm{t}=2.599, \mathrm{p}=0.01$ ).

There was no statistically significant association of anti-HBs status following the $4^{\text {th }}$ dose of vaccine with sex (Fisher's exact test, $p=0.653$ ), smoking $\left(\chi^{2}=0.751, d f=2, p=0.687\right)$, body mass index (Fisher's exact test, $p=0.114$, for the comparison of underweight plus healthy weight versus overweight plus obesity), presence of chronic conditions $\left(\chi^{2}=1.100\right.$, $d f=2, p=0.577)$, and the interval between the $3^{\text {rd }}$ dose of HB vaccine and the post-vaccination testing (Student's $T$ test, $t=-355, p=0.723$ ).

Among the $25 \mathrm{HCW}$ who were anti-HBs-negative after the $4^{\text {th }}$ dose of HB vaccine, $15(60 \%)$ seroconverted after the $6^{\text {th }}$ dose of the vaccine and 4 were true non-responders (the interval between the $6^{\text {th }}$ dose and the test ranged from 1 to 8 months, with a mean of 3.2 months). One of the non-responders seroconverted after the $7^{\text {th }}$ dose. One HCW was $\mathrm{HBsAg}$-positive. Figure 1 presents an algorithm of the study's events.

Twenty-four (14.1\%) of the $170 \mathrm{HCW}$ did not complete the proposed revaccination and post-vaccination testing.

The status of the $170 \mathrm{HCW}$ who were anti-HBs-negative after a primary 3-dose HB vaccination series could have been due to nonresponse to the vaccine or to waning immunity. Most (74.1\%) of them were anti-HBs-positive after the $4^{\text {th }}$ dose of the vaccine. Among the 25 HCW who did not respond to the $4^{\text {th }}$ dose, $60 \%$ seroconverted after the $6^{\text {th }}$ dose of $\mathrm{HB}$ vaccine; one $\mathrm{HCW}$ was $\mathrm{HBsAg}$-positive, and only 4 (2.7\%) of the $146 \mathrm{HCW}$ who completed the study did not respond to a $2^{\text {nd }}$ fullcourse $\mathrm{HB}$ vaccination and were considered true non-responders, even though one of them was anti-HBs-positive after the $7^{\text {th }}$ dose of HB vaccine.

TABLE 1 - Characteristics of the 170 healthcare workers who were anti-HBs negative after a primary 3-dose hepatitis B vaccination series, according to their anti-HBs status following the $4^{\text {th }}$ dose of the vaccine.

\begin{tabular}{|c|c|c|c|c|c|c|}
\hline \multirow[b]{4}{*}{ HCW characteristics (total)* } & \multicolumn{6}{|c|}{ Anti-HBs status after the $4^{\text {th }}$ dose of HB vaccine } \\
\hline & \multirow{2}{*}{\multicolumn{2}{|c|}{$\begin{array}{c}\text { positive }(\mathrm{n}=126) \\
(\geq 10 \mathrm{mIU} / \mathrm{mL})\end{array}$}} & \multirow{2}{*}{\multicolumn{2}{|c|}{$\begin{array}{c}\text { negative }(\mathrm{n}=25) \\
(<10 \mathrm{mlU} / \mathrm{mL})\end{array}$}} & \multirow{2}{*}{\multicolumn{2}{|c|}{$\begin{array}{l}\text { not done } \\
(n=19)\end{array}$}} \\
\hline & & & & & & \\
\hline & $\mathrm{n}$ & $\%$ & $\mathrm{n}$ & $\%$ & $n$ & $\%$ \\
\hline \multicolumn{7}{|l|}{ Sex } \\
\hline female (109) & 77 & 70.6 & 17 & 15.6 & 15 & 13.8 \\
\hline male (61) & 49 & 80.3 & 8 & 13.1 & 4 & 6.6 \\
\hline \multicolumn{7}{|c|}{ Age at primary HB vaccination series (years) (136) } \\
\hline $\min -\max$ & 6 & 63 & 18 & 55 & 8 & 42 \\
\hline mean \pm std. dev. & \multicolumn{2}{|c|}{$30.9 \pm 12.9$} & \multicolumn{2}{|c|}{$37.0 \pm 13.3$} & \multicolumn{2}{|c|}{$23.1 \pm 9.6$} \\
\hline \multicolumn{7}{|l|}{ Smoking (168) } \\
\hline yes (18) & 15 & 83.3 & 2 & 11.1 & 1 & 5.5 \\
\hline no (150) & 109 & 72.7 & 23 & 15.3 & 18 & 12.0 \\
\hline \multicolumn{7}{|l|}{ Body mass index (162) } \\
\hline <18.5 (underweight) (7) & \multicolumn{2}{|c|}{4} & \multicolumn{2}{|c|}{2} & \multicolumn{2}{|r|}{1} \\
\hline 18.5-24.9 (healthy weight) (88) & \multicolumn{2}{|c|}{68} & \multicolumn{2}{|c|}{8} & \multicolumn{2}{|c|}{12} \\
\hline 25-29.9 (overweight) (49) & \multicolumn{2}{|c|}{34} & \multicolumn{2}{|c|}{10} & \multicolumn{2}{|r|}{5} \\
\hline$\geq 30$ (obesity) (18) & \multicolumn{2}{|c|}{13} & \multicolumn{2}{|c|}{4} & \multicolumn{2}{|r|}{1} \\
\hline \multicolumn{7}{|c|}{ Chronic condition/immunodepression (169) } \\
\hline yes (17) & 12 & 70.6 & 4 & 23.5 & 1 & 5.9 \\
\hline no (152) & 113 & 74.3 & 21 & 13.8 & 18 & 11.8 \\
\hline \multicolumn{7}{|c|}{ Interval between $3^{\text {rd }}$ dose of HB vaccine and testing (months) (156) } \\
\hline $\min -\max$ & 8 & 193 & 8 & 144 & 3 & 137 \\
\hline mean \pm Standard deviation & \multicolumn{2}{|c|}{$75.8+42.3$} & \multicolumn{2}{|c|}{$72.5 \pm 39.3$} & \multicolumn{2}{|c|}{$67.2+39.0$} \\
\hline
\end{tabular}

Anti-HBs: antibodies to hepatitis B surface; HCW: healthcare workers; HB: hepatitis B; *total number of subjects varies due to missing data. 


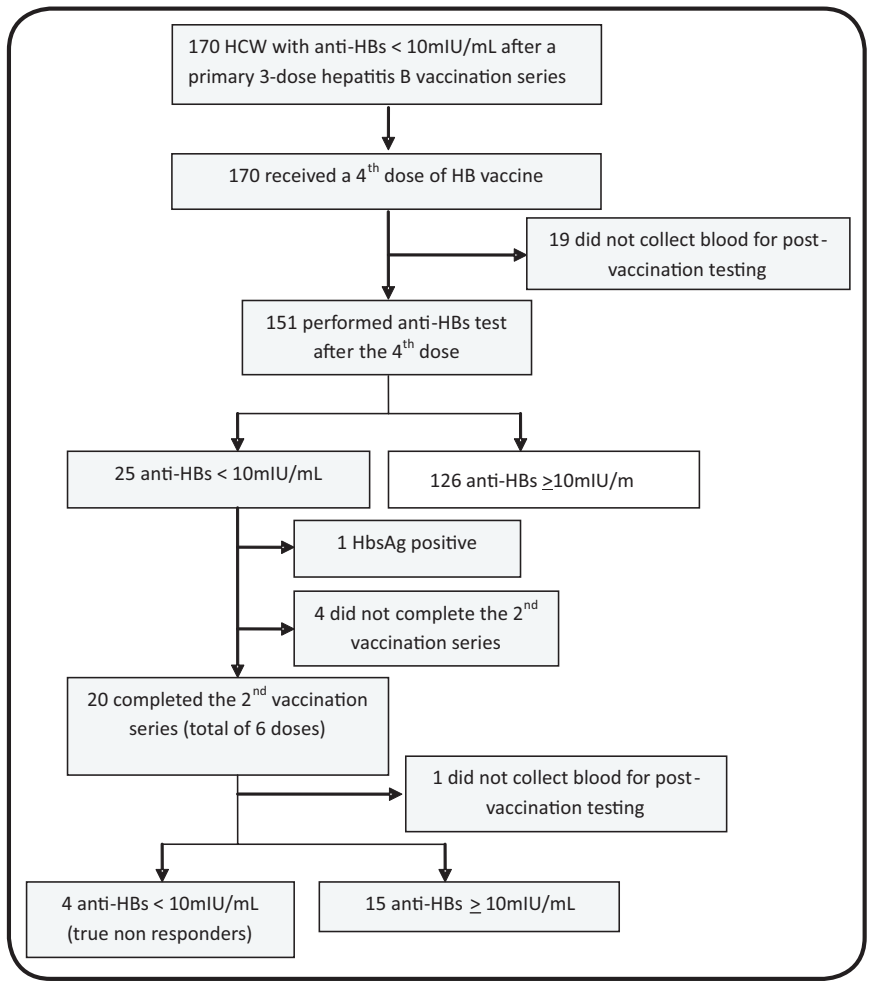

FIGURE1 - Algorithm of study events for 170 healthcare workers with anti-HBs negative after a primary 3-dose hepatitis B vaccination series.

Anti-HBs: antibodies to hepatitis B surface; HB: hepatitis B; HCW: healthcare workers.

The management of HCW who were not tested immediately after a complete primary $\mathrm{HB}$ vaccination series is controversial ${ }^{1}$. In this case, some authors argue that HCW do not need to be tested unless they have been exposed ${ }^{7}$. However, knowledge of post-vaccination antiHBs status is important to appropriate post-exposure management. In case of occupational exposure to blood and body fluids, unknown anti-HBs status is a cause of anxiety for both the HCW themselves and the health professionals responsible for their care. It may lead to hasty decisions regarding prophylactic measures and unnecessary use of $\mathrm{HB}$ immune globulin ( $\mathrm{HBI}$ ). This is of particular concern in countries with limited resources.

The HCW enrolled in this study were tested for anti-HBs during routine assessment by the occupational health service during admittance exams or periodic check-ups. These HCW did not report an occupational exposure to biological material previous to the anti-HBs negative testing. None of them received $\mathrm{HBIg}$, and most of them responded to the $4^{\text {th }}$ dose of $\mathrm{HB}$ vaccine, making it unnecessary to complete the $2^{\text {nd }}$ vaccination series, thus saving time and influencing adherence.

Routine booster doses of $\mathrm{HB}$ vaccine and further periodic anti$\mathrm{HBs}$ testing are not recommended for healthy $\mathrm{HCW}$, once response to a full vaccination course has been confirmed by post-vaccination testing ${ }^{1-2,8}$. However, sometimes the post-vaccination test is performed more than six months after the last $\mathrm{HB}$ vaccine dose. The results of this study strengthen the proposed strategy of rechecking anti-HBs status after the $4^{\text {th }}$ dose of the vaccine in such cases. HCW who fail to respond to the $4^{\text {th }}$ dose of $\mathrm{HB}$ vaccine should be investigated for $\mathrm{HB}$ infection, in case pre-vaccination testing was not performed, and given a $2^{\text {nd }}$ full-course vaccination, followed by retesting of anti-HBs status within 30 to 90 days of the last dose.
Age >40 years; obesity; smoking; presence of chronic conditions, such as human immunodeficiency virus (HIV) infection, advanced liver disease, chronic renal failure, and immunosuppression; and certain human leukocyte antigen (HLA) haplotypes have been associated with decreased response to $\mathrm{HB}$ vaccine ${ }^{1}$. In this study, no association was observed between negative anti-HBs after the $4^{\text {th }}$ dose and age, sex, smoking, body mass index, and chronic conditions, probably due to the small sample size.

The transmission of the $\mathrm{HB}$ virus in healthcare settings still is a problem ${ }^{9}$. A recent study in São José do Rio Preto, State of São Paulo, showed significantly higher prevalence of $\mathrm{HB}$ among HCW $(0.8 \%)$ than among blood-donor candidates $(0.2 \%)^{10}$.

However, the adherence of HCW to $\mathrm{HB}$ vaccination and postvaccination testing is poor. In the United States, $75 \%$ of HCW working in hospitals and with frequent or potential exposure to blood or other potentially infectious material were estimated to have been vaccinated against $\mathrm{HB}^{11}$. In a survey in Belo Horizonte, State of Minas Gerais, $73.8 \%$ of dentists reported having received a complete 3 -dose HB vaccination series, and only $14.8 \%$ reported having performed the post-vaccination test ${ }^{12}$. In Sertãozinho, State of São Paulo, $82.2 \%$ of dentists reported 3 or more doses of the vaccine, but only $12.8 \%$ of those who had received at least one vaccine dose reported post-vaccination testing ${ }^{13}$. Among primary healthcare personnel in Florianópolis, State of Santa Catarina, 64.1\% of $1,249 \mathrm{HCW}$ reported a complete $\mathrm{HB}$ vaccination, and $33 \%$ of them had undergone post-vaccination testing ${ }^{14}$. In this study, $14.1 \%$ of $\mathrm{HCW}$ dropped out, despite having been offered free vaccination and testing at the workplace and having been called up in case of delay. Non-adherence was greater among younger HCW.

The results of this study suggest that $\mathrm{HCW}$ with a full $\mathrm{HB}$ vaccination course whose post-vaccination test was not performed within the recommended 30- to 90-day interval after the last dose of the HB vaccine may be given a $4^{\text {th }}$ dose followed by a post-vaccination test. This approach was confirmed as practical and effective. Simplifying the vaccination process may help to enhance HCW adherence.

\section{CONFLICT OF INTEREST}

The authors declare that there is no conflict of interest.

\section{ABSTRACT IN PORTUGUESE}

\section{Revacinação contra hepatite B para profissionais de saúde com anti-HBs negativo após receber esquema primário de vacinação completo}

Introdução: Esse estudo avaliou a resposta à revacinação contra hepatite $B(\mathrm{HB})$ entre profissionais de saúde (PS) com anti-HBs negativo após esquema de vacinação completo. Métodos: PS cujo anti-HBs foi realizado > 90 dias após a última dose do esquema vacinal receberam 4a dose da vacina. O anti-HBs foi repetido 30-90 dias após. Resultados: Entre 170 PS, $126(74,1 \%)$ tiveram anti-HBs positivo após a 4ạ dose. Conclusões: Repetir o teste sorológico após a 4a dose é estratégia prática caso o anti-HBs tenha sido realizado > 90 dias após a última dose da vacina.

Palavras-chaves: Vacinação contra hepatite B. Profissionais de saúde. 


\section{REFERENCES}

1. Hepatitis B vaccines. Wkly Epidemiol Rec 2009; 84:405-419.

2. Mast EE, Margolis HS, Fiore AE, Brink EW, Goldstein ST, Wang SA, et al. A comprehensive immunization strategy to eliminate transmission of hepatitis B virus infection in the United States: recommendations of the Advisory Committee on Immunization Practices (ACIP) part 1: immunization of infants, children, and adolescents. MMWR Recomm Rep 2005; 54 (RR-16):1-31.

3. Floreani A, Baldo V, Cristofoletti M, Renzulli G, Valeri A, Zanetti C, et al. Long-term persistence of anti-HBs after vaccination against HBV: an 18 year experience in health care workers. Vaccine 2004; 26:22:607-610.

4. Poland GA. Hepatitis B immunization in health care workers. Dealing with vaccine nonresponse. Am J Prev Med 1998;15:73-77.

5. Sjogren MH. Prevention of hepatitis $B$ in nonresponders to initial hepatitis $B$ virus vaccination. Am J Med 2005;118 (suppl):10A:34S-39S.

6. Mast EE, Weinbaum CM, Fiore AE, Alter MJ, Bell BP, Finelli $L$, et al. A comprehensive immunization strategy to eliminate transmission of hepatitis $B$ virus infection in the United States: recommendations of the Advisory Committee on Immunization Practices (ACIP) Part II: immunization of adults. MMWR Recomm Rep 2006; 55 (RR-16):1-33.

7. Centers for Disease Control and Prevetion. Updated U.S. Public Health Service Guidelines for the Management of Occupational Exposures to HBV, HCV, and HIV and Recommendations for Postexposure Prophylaxis. Atlanta: MMWR Recomm Rep 2001; 50 (RR-11):1-52.

8. Zanetti AR, Mariano A, Romano L, D’Amelio R, Chironna M, Coppola RC, et al. Longterm immunogenicity of hepatitis $B$ vaccination and policy for booster: an Italian multicentre study. Lancet 2005; 366:1379-1384.

9. Lanini S, Puro V, Lauria FN, Fusco FM, Nisii C, Ippolito G. Patient to patient transmission of hepatitis $B$ virus: a systematic review of reports on outbreaks between 1992 and 2007. BMC Med 2009; 7:15

10. Ciorlia LA, Zanetta DM. Hepatitis B in healthcare workers: prevalence, vaccination and relation to occupational factors. Braz J Infect Dis 2005; 9:384-389.

11. Simard EP, Miller JT, George PA, Wasley A, Alter MJ, Bell BP, et al. Hepatitis B vaccination coverage levels among healthcare workers in the United States, 20022003. Infect Control Hosp Epidemiol 2007; 28:783-790.

12. Resende VL, Abreu MH, Paiva SM, Teixeira R, Pordeus IA. Concerns regarding hepatitis $B$ vaccination and post-vaccination test among Brazilian dentists. Virol J 2010; 7:154.

13. Bellissimo-Rodrigues WT, Machado AA, Bellissimo-Rodrigues F, Nascimento MP, Figueiredo JF. Prevalence of hepatitis $B$ and $C$ among Brazilian dentists. Infect Control Hosp Epidemiol 2006; 27:887-888.

14. Garcia LP, Facchini LA. Hepatitis B vaccination among primary health care workers. Cad Saude Publica 2008; 24:1130-1140. 